$\sqrt{6}$

EDITOR'S

CHOICE

\title{
Disorders of iron metabolism. Part II: iron deficiency and iron overload
}

\author{
Manuel Muñoz, ${ }^{1}$ José Antonio García-Erce, ${ }^{2}$ Ángel Francisco Remacha ${ }^{3}$
}

${ }^{1}$ Transfusion Medicine, School of Medicine, University of Malaga, Malaga, Spain ${ }^{2}$ Hematology and Hemotherapy, University Hospital Miguel Servet, Zaragoza, Spain ${ }^{3}$ Hematology and Hemotherapy, Complejo Hospitalario de Toledo, Toledo, Spain

\section{Correspondence to} Professor Manuel Muñoz, Medicina Transfusional, Facultad de Medicina, Campus de Teatinos, s/n, 29071-Málaga Spain; mmunoz@uma.es

All authors have equally contributed to this paper.

Accepted 15 November 2010 Published Online First 20 December 2010
ABSTRACT

Main disorders of iron metabolism Increased iron requirements, limited external supply, and increased blood loss may lead to iron deficiency (ID) and iron deficiency anaemia. In chronic inflammation, the excess of hepcidin decreases iron absorption and prevents iron recycling, resulting in hypoferraemia and iron restricted erythropoiesis, despite normal iron stores (functional iron deficiency), and finally anaemia of chronic disease (ACD), which can evolve to ACD plus true ID (ACD+ID). In contrast, low hepcidin expression may lead to hereditary haemochromatosis (HH type I, mutations of the HFE gene) and type II (mutations of the hemojuvelin and hepcidin genes). Mutations of transferrin receptor 2 lead to $\mathrm{HH}$ type III, whereas those of the ferroportin gene lead to $\mathrm{HH}$ type IV. All these syndromes are characterised by iron overload. As transferrin becomes saturated in iron overload states, non-transferrin bound iron appears. Part of this iron is highly reactive (labile plasma iron), inducing free radical formation. Free radicals are responsible for the parenchymal cell injury associated with iron overload syndromes.

Role of laboratory testing in diagnosis In iron deficiency status, laboratory tests may provide evidence of iron depletion in the body or reflect iron deficient red cell production. Increased transferrin saturation and/or ferritin levels are the main cues for further investigation of iron overload. The appropriate combination of different laboratory tests with an integrated algorithm will help to establish a correct diagnosis of iron overload, iron deficiency and anaemia.

Review of treatment options Indications, advantages and side effects of the different options for treating iron overload (phlebotomy and iron chelators) and iron deficiency (oral or intravenous iron formulations) will be discussed.

\section{INTRODUCTION}

Iron is an essential micronutrient, as it is required for an adequate erythropoietic function, oxidative metabolism and cellular immune response. Absorption of dietary iron ( $1-2 \mathrm{mg} /$ day) is tightly regulated, and just balanced with losses, because there is no active iron excretion. Dietary iron is found in haem (10\%) and non-haem (ionic, 90\%) forms and their absorption occurs at the apical surface of duodenal enterocytes via different mechanisms. Iron is exported across the basolateral membrane of the enterocyte into the circulation (absorbed iron), where it binds to transferrin and is transported to sites of use and storage. Transferrin-bound iron enters target cells-mainly erythroid cells, but also immune and hepatic cells-through a process of receptor-mediated endocytosis. Senescent erythrocytes undergo phagocytosis by reticuloendothelial system (RES) macrophages, haem is metabolised by heme-oxygenase, and iron is stored as ferritin. Iron is later released from macrophages and bound by transferrin, which transports iron to the bone marrow. This internal turnover of iron is essential to meet the requirements for erythropoiesis (20-30 mg/day). ${ }^{1}$ After reviewing the main pathways of iron metabolism (namely, iron absorption, distribution, usage, storage and recycling) and their regulation, ${ }^{1}$ in this paper we will review iron deficiency (ID) and iron overload statuses.

\section{IRON DEFICIENCY}

Under physiological conditions, there is a balance between iron absorption, iron transport and iron storage in the human body. However, ID and iron deficiency anaemia (IDA) may result from the interplay of three distinct risk factors: increased iron requirements, limited external supply and increased blood loss (box 1). ${ }^{2}$ ID can be either absolute or functional. In absolute ID, iron stores are depleted; in functional iron deficiency (FID), iron stores, although replete, cannot be mobilised as fast as necessary from the macrophages of the RES to the bone marrow.

\section{Laboratory assessment of ID}

Laboratory tests for investigating ID fall into two categories: measurements providing evidence of iron depletion in the body, and measurements reflecting iron-deficient red cell production ${ }^{3}$ (table 1 ). The appropriate combination of these laboratory tests will help to establish a correct diagnosis of anaemia and ID status (figure 1). ${ }^{4}$

\section{ID without anaemia}

A normal haemoglobin $(\mathrm{Hb})$ level does not exclude ID, because an individual with normal body iron stores must lose a large portion of body iron before the $\mathrm{Hb}$ falls below the laboratory definition of anaemia (generally, $\mathrm{Hb}<12 \mathrm{~g} / \mathrm{dl}$ for women and $\mathrm{Hb}$ $<13 \mathrm{~g} / \mathrm{dl}$ for men), although higher levels have been recently proposed, according to gender, age and racial origin. ${ }^{5}$ In non-anaemic patients, the most important clinical clue of ID is the symptom of chronic fatigue (iron is required for the enzymes involved in oxidative metabolism). However, it is of little screening value because clinicians rarely consider the presence of ID in patients who are not anaemic, and therefore ID is invariably diagnosed in the laboratory. ${ }^{3}$ A normal $\mathrm{Hb}$ level with a mean corpuscular $\mathrm{Hb}(\mathrm{MCH})$ in the lower limit of normality (normal range 28-35 pg) or an increased red cell distribution width (RDW, normal range 11-15) indicate mild ID without anaemia. However, although RDW may be the earliest 


\section{Box 1 Main causes of iron deficiency}

Increased demands

- Growth during infancy and childhood

- Treatment with erythropoiesis-stimulating agents

Limited external supply

- Poor intake

- Inappropriate diet with deficit in bioavailable iron and/or ascorbic acid

- Malabsorption

- Gastric resection

- Helicobacter pylori infection (even without significant bleeding)

- Malabsorption syndromes (Crohn disease and coeliac disease)

- Drug interference (gastric anti-acid agents and antisecretory drugs)

Increased losses

- Phlebotomy

- Blood donation

- Dialysis (particularly haemodialysis)

- Haemorrhage

- Surgery

- Trauma

- Gastrointestinal bleeding

- Genitourinary bleeding

- Respiratory tract bleeding

indicator of ID, the main laboratory finding is a low ferritin level $(1 \mathrm{ng} / \mathrm{ml}$ of serum ferritin corresponds to approximately $8 \mathrm{mg}$ of stored iron). Thus, measurement of ferritin provides the most useful indirect estimate of body iron stores. In the absence of inflammation (eg, serum concentrations of $\mathrm{C}$ reactive protein $(\mathrm{CRP})<0.5 \mathrm{mg} / \mathrm{dl}$ ), true ID can be defined by a ferritin level $<15-30 \mathrm{ng} / \mathrm{ml}$. In the presence of inflammation, a normal ferritin level does not exclude ID, and transferrin saturation (TSAT) should also be measured. As transferrin is the only ironbinding protein involved in iron transport, TSAT reflects iron availability for the bone marrow. Thus, in the presence of inflammation, true ID could be defined by a ferritin concentration $<100 \mathrm{ng} / \mathrm{ml}$ and a TSAT $<20 \%$, whereas FID is defined by a ferritin concentration $>100 \mathrm{ng} / \mathrm{ml}$ and a TSAT $<20 \%$. FID may also occur in response to the therapeutic use of erythropoiesis-stimulating agents, which place a significant demand on iron stores that may surpass the iron-release capacity of the RES. ${ }^{6}$

\section{Iron deficiency anaemia}

Patients should be considered to suffer from IDA when they present with low $\mathrm{Hb}$ (men $<13 \mathrm{~g} / \mathrm{dl}$, and women $<12 \mathrm{~g} / \mathrm{dl}$ ), TSAT $(<20 \%)$ and ferritin concentrations $(<30 \mathrm{ng} / \mathrm{ml})$ but no signs of inflammation. ${ }^{3}$ The $\mathrm{MCH}$ rather than mean corpuscular volume (MCV) has become the most important red cell marker for detecting ID in circulating red blood cells (figure 1). MCV is a reliable and widely available measurement, but it is a relatively late indicator in patients who are not actively bleeding. In the presence of low MCV, differential diagnosis must be made with thalassaemia (normal RDW). In addition, patients may present with IDA and without microcytosis when there is coexisting vitamin $\mathrm{B}_{12}$ or folate deficiency, post-bleeding reticulocytosis, initial response to oral iron treatment, alcohol intake or mild myelodysplasia.

A truncated, soluble form of the transferrin receptor (sTfR) can be detected in human serum, and its concentration is proportional to the total amount of cell surface transferrin receptors. Normal median concentrations are $1.2-3.0 \mathrm{mg} / \mathrm{l}$, although the level is not standardised and depends on which reagent kit is used. Increased sTfR concentrations indicate ID even during the anaemia of chronic disease. However, increased sTfR levels can also be found in increased erythropoietic activity without ID, during reticulocytic crisis, and in congenital dyserythropoietic anaemias. In contrast, lower sTfR concentrations may reflect decreased number of erythroid progenitors. ${ }^{7} 8$ Nevertheless, although sTfR levels are usually high or very high in uncomplicated IDA, they are not usually required for the diagnosis.

\section{Anaemia of chronic disease}

Patients should be considered to have anaemia of chronic disease (ACD), also called anaemia of inflammation, when they

Table 1 Main laboratory tests for the assessment of iron depletion

\begin{tabular}{|c|c|c|c|}
\hline \multirow[b]{2}{*}{ Laboratory test } & \multicolumn{3}{|l|}{ Normal values } \\
\hline & Conventional units & Conversion factor $\dagger$ & SI units \\
\hline \multicolumn{4}{|l|}{ Iron status in the body } \\
\hline - Serum iron & $50-180 \mu \mathrm{g} / \mathrm{dl}$ & $\times 0.179$ & $9-32 \mu \mathrm{mol} / \mathrm{l}$ \\
\hline Transferrin & $200-360 \mathrm{mg} / \mathrm{dl}$ & $\times 0.01$ & $2-3.6 \mathrm{~g} / \mathrm{l}$ \\
\hline - Transferrin saturation & $20-50 \%$ & & \\
\hline - Ferritin (Ft) & $30-300 \mathrm{ng} / \mathrm{ml}$ & $\times 2.247$ & $65-670 \mathrm{pmol} / \mathrm{l}$ \\
\hline - Soluble transferrin receptors $(\mathrm{sTfR})^{*}$ & $0.76-1.76 \mathrm{mg} / \mathrm{l}$ & & $6.4-25.7 \mathrm{nmol} / \mathrm{l}$ \\
\hline - Ratio of sTfR to serum Ft (sTfR/log Ft) & $<1$ & & \\
\hline \multicolumn{4}{|l|}{ Iron-deficient red cell production } \\
\hline - Haemoglobin & $\begin{array}{l}12-16 \mathrm{~g} / \mathrm{dl} \text { (women); } \\
13-17 \mathrm{~g} / \mathrm{dl} \text { (men) }\end{array}$ & $\times 0.6206 \ddagger$ & $\begin{array}{l}7.5-10 \mathrm{mmol} / \mathrm{l} \text { (women); } \\
8-10.5 \mathrm{mmol} / \mathrm{l} \text { (men) }\end{array}$ \\
\hline - Mean corpuscular volume & $80-100 \mathrm{fl}$ & & \\
\hline - Red cell distribution width & $11-15$ & & \\
\hline Mean corpuscular haemoglobin & $28-35 \mathrm{pg}$ & & \\
\hline Hypochromic red cells & $<5 \%$ & & \\
\hline - Reticulocyte haemoglobin content & $28-35 \mathrm{pg}$ & & \\
\hline
\end{tabular}

*Normal values may differ depending on the assay used.

†To convert the concentration values in conventional units into SI units multiply values by the conversion factor.

łIn fact, although widely used, this factor allows for the calculation the molar concentration of haemoglobin subunits. Thus, the molar concentration of haemoglobin (molecular mass $64 \mathrm{kDa}$ ) is fourfold lower $(2-3 \mathrm{mmol} / \mathrm{l})$. 


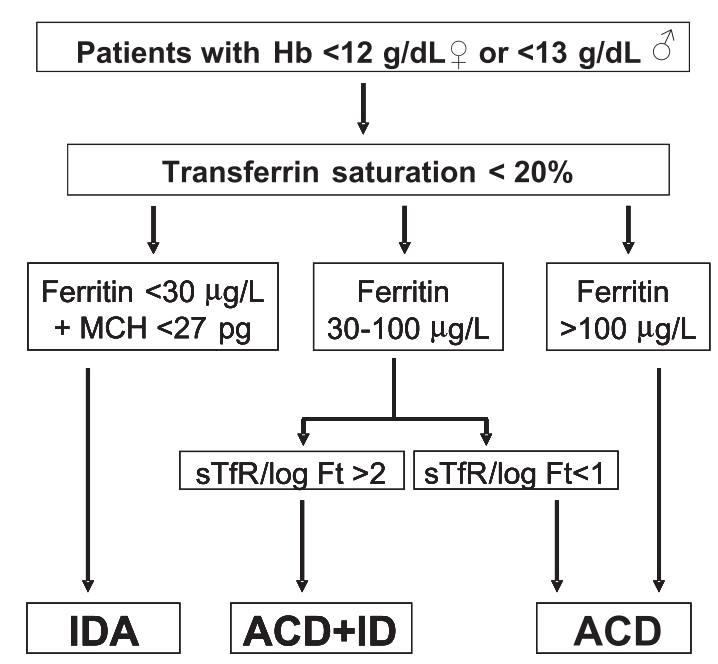

Figure 1 A simplified algorithm for the diagnosis of iron deficiency anemia (modified from Weiss and Goodnough $(2005)^{4}$ ). ACD, anaemia of chronic disease; $\mathrm{Hb}$, haemoglobin; ID, iron deficiency; IDA, iron deficiency anemia; MCH, mean corpuscular haemoglobin; sTfR, serum transferrin receptor.

have: (1) evidence of chronic inflammation (eg, high CRP level); (2) $\mathrm{Hb}$ concentration of $<13 \mathrm{~g} / \mathrm{dl}$ for men and $<12 \mathrm{~g} / \mathrm{dl}$ for women; and (3) a low TSAT $(<20 \%)$, but normal or increased serum ferritin concentration $(>100 \mathrm{ng} / \mathrm{ml})$ or low serum ferritin concentration $(30-100 \mathrm{ng} / \mathrm{ml})$ and a sTfR/log ferritin ratio $<1 .{ }^{4-11} \mathrm{ACD}$, as well as FID, is frequent among patients with inflammatory disease without apparent blood loss (eg, rheumatoid arthritis, renal failure or chronic hepatitis).

\section{ACD with true ID}

Patients should be considered to have ACD with true ID (ACD+ ID) when they have: (1) a chronic inflammation; (2) $\mathrm{Hb}$ concentration of $<13 \mathrm{~g} / \mathrm{dl}$ for men and $<12 \mathrm{~g} / \mathrm{dl}$ for women; and (3) low TSAT $(<20 \%)$, a serum ferritin concentration $>30 \mathrm{ng} / \mathrm{ml}$ and $<100 \mathrm{ng} / \mathrm{ml}$ and a sTfR/log ferritin ratio $>2 .{ }^{49-11}$ This type of anaemia is more frequent in patients with inflammatory diseases and chronic blood loss (eg, inflammatory bowel disease). There are several important haematological indices that may also help in the diagnosis of ID in ACD, although they can only be measured by specific haematology analysers. Reticulocyte $\mathrm{Hb}$ content and hypochromic red blood cells are reported by the Bayer Advia 120 haematology analyser (Siemens Healthcare Diagnostics, Deerfield, Illinois, USA). In non-ferropenic patients, the 2.5 percentile values are $28 \mathrm{pg}$ for reticulocyte $\mathrm{Hb}$ content and $5 \%$ for hypochromic red blood cells, whereas $\mathrm{MCH}$ is $\geq 27$ pg. $^{8}$ The Sysmex XE-2100 haematology analyser (Sysmex, Mundelein, Illinois, USA) determines RET-Y, which can be considered as the reticulocyte $\mathrm{Hb}$ equivalent, as well as RBC-Y, which can be considered as the erythrocyte Hb equivalent. ${ }^{12-14}$ These haematological indexes are direct indicators of FID in contrast to the majority of biochemical markers, which measure FID indirectly via iron-deficient erythropoiesis and demonstrate weaknesses in the diagnosis of FID as defined by haematological indices. ${ }^{8}$ New haematological indexes are being developed for other haematology analysers, such as the microcytic anaemia factor or microcytic factor and low $\mathrm{Hb}$ density determined by the Beckman Coulter LH 750 (Beckman Coulter, Brea, California, USA), and their clinical utility in the diagnosis of ID will be evaluated in the future (http://www.wipo.int/pctdb/en/wo. jsp?IA=WO2007035916\&DISPLAY=DESC).
Interestingly, although hepcidin affects iron traffic in $\mathrm{ACD}$ and $A C D+I D$, individuals with $A C D+I D$ have significantly lower hepcidin levels than ACD subjects, and ACD +ID individuals, in contrast to ACD subjects, are able to absorb some dietary iron from the gut and to mobilise some iron from macrophages. Thus, hepcidin determination may also aid in differentiating between $\mathrm{ACD}$ and $\mathrm{ACD}+\mathrm{ID}$ and in selecting the appropriate therapy for these patients. ${ }^{9}$

\section{Management of ID \\ Oral iron}

Oral iron supplementation is adequate in most clinical conditions. In the absence of inflammation or significant ongoing blood loss, the administration of oral iron, generally as ferrous salts, can correct the anaemia, provided significant doses can be tolerated. However, although conventional wisdom 'says' that up to $200 \mathrm{mg}$ of elemental iron per day is required to correct IDA, this is incorrect and lower doses can also be efficacious. ${ }^{15}$ Early studies indicated that the co-administration of iron with vitamin $\mathrm{C}$ might be of benefit in enhancing iron absorption, since, in theory, more ferrous iron is maintained in solution. However reports have indicated that such co-administration can induce severe toxicity in the gastrointestinal tract. ${ }^{16}$ Moreover, classically, oral iron intake separately from meals is recommended for increasing its absorption but it enhances digestive intolerance, and therefore decreases compliance. In addition, the absorption of iron salts can be diminished by co-administration of some antibiotics (mainly quinolones, doxycycline, tretracyclines, chloramphenicol or penicillamine), proton pump inhibitors and anti-acid medication (aluminium, bicarbonate, zinc or magnesium salts), levodopa, levothyroxine, cholestyramine, phytates (high-fibre diets), soy products, ibandronate, etidronate, tannates, calcium and phenolic compounds (coffee, tea), whereas amino acids seem to act as enhancers of iron absorption. ${ }^{3} 16$

On the other hand, non-absorbed iron salts may produce a variety of highly reactive oxygen species including hypochlorous acid, superoxides and peroxides, which may lead to digestive intolerance, causing nausea, flatulence, abdominal pain, diarrhoea or constipation, and black or tarry stools, and perhaps could activate relapsed inflammatory bowel disease. Therefore, lower doses of iron salts (eg, 50-100 mg of elemental iron) should be recommended. ${ }^{15}$

Total iron deficit (TID) can be calculated using the Ganzoni formula: TID $(\mathrm{mg})=$ weight $(\mathrm{kg}) \times($ ideal $\mathrm{Hb}-$ actual $\mathrm{Hb})(\mathrm{g} /$ dl) $\times 0.24+$ depot iron $(500 \mathrm{mg})$. According to this formula, a person weighing $70 \mathrm{~kg}$ with a $\mathrm{Hb}$ level of $9 \mathrm{~g} / \mathrm{dl}$ would have a body iron deficit of about $1400 \mathrm{mg}$. Following the administration of oral iron, it takes $2-2.5$ weeks for the Hb to start rising, 2 months for it to return to normal levels, and 6 months for iron stores to be replete. ${ }^{17}$

\section{Parenteral iron}

Classically, parenteral iron is indicated in situations such as intolerance, contraindications or inadequate response to oral iron. However, parenteral iron is now a useful treatment in cases where there is a short time to surgery, severe anaemia, especially if accompanied by significant ongoing bleeding, use of erythropoiesis-stimulating agents, etc. ${ }^{18}$ Modern intravenous iron formulations have emerged as safe and effective alternatives for anaemia management, as they present several advantages over oral supplementation. The administration of intravenous iron enables a fivefold erythropoietic response to significant bloodloss anaemia in normal individuals, ${ }^{19} \mathrm{Hb}$ starts to rise after a few 
days, the percentage of responding patients is higher and iron stores are replete. Boosting iron stores is an advantage, particularly for patients receiving erythropoiesis-stimulating agents. ${ }^{17}$

Seven different products are principally used in clinical practice: iron gluconate, iron sucrose, high molecular weight iron dextran (HMWID), low molecular weight iron dextran (LMWID), ferric carboxymaltose, iron isomaltoside 1000 and ferumoxytol (table 2). Most intravenous iron agents are colloids with spheroidal iron-carbohydrate nanoparticles. Each particle consists of and iron-oxyhydroxide core (Fe (III)) and a carbohydrate shell that stabilises the iron-oxyhydroxide core. However, the structure of iron isomaltoside 1000 is somehow different, as the linear oligosaccharide isomaltoside 1000 allows the formation of a matrix with interchanging iron and carbohydrate, instead of a classical spheroidal iron carbohydrate nanoparticle. Complexes can generally be classified as labile or robust (kinetic variability), and as weak or strong (thermodynamic variability), with all possible intermediates.

Each iron product is taken up into the RES, where the shell is degraded for iron to become bioavailable. The efficacy of intravenous iron is directly related to the amount of iron administered, but differences in core size and carbohydrate chemistry determine pharmacological and biological differences between the different iron complexes. These differences include clearance after injection, iron release in vitro, early evidence of iron bioactivity in vivo, and maximum tolerated dose and rate of infusion, as well as effects on oxidative markers, propensity for inducing hypophosphataemia, and propensity to cause transient proteinuria following administration. ${ }^{20-25}$

Although their efficacy for treating anaemia has been consistently proved in a variety of clinical settings, ${ }^{26}$ all intravenous preparations have been reported to cause anaphylactoid reactions, which are characterised by nausea, hypotension, tachycardia, chest pain, dyspnoea (lung oedema) and bilateral oedema of the hands and feet, and they should not be misread as anaphylaxis. ${ }^{20}$ However, iron dextran complexes may cause well-known dextran-induced anaphylactic reactions, which are significantly more frequent with HMWID than with LMWID. Although the exact mechanism of the anaphylactic reaction to iron dextran has not been clarified, it seems to be related to the antibody-mediated release of mediators by mast cells. Nevertheless, HMWID is not commercially available in Europe; the National Comprehensive Cancer Network recommends against the use of Dexferrum, and the US Food and Drug Administration has changed HMWID (Dexferrum) labelling to warn that it is not clinically interchangeable with LMWID (INFeD, CosmoFer). ${ }^{27} 28$ The regulatory application for iron isomaltoside 1000 (Monofer) includes references to general intravenous iron documentation, including evidence with iron dextran, but the regulatory authorities recognise the unique properties of isomaltoside 1000 (a non-anaphylactic carbohydrate), and there is no requirement for a test dose application, which is always the case with iron dextran. Therefore, with the exception of HMWID (increased rates of severe side-effects and deaths), the acute safety differences among intravenous iron products are small and clinically irrelevant when given at the recommended doses, though comparator trials are needed to be certain.

Current information on the relationship between intravenous iron and infection, and between intravenous iron and oxidative stress, deserves special consideration. Elemental iron is an essential growth factor for bacteria, with many species expressing iron transport proteins that compete with transferrin, and it has long been suggested that patients with iron

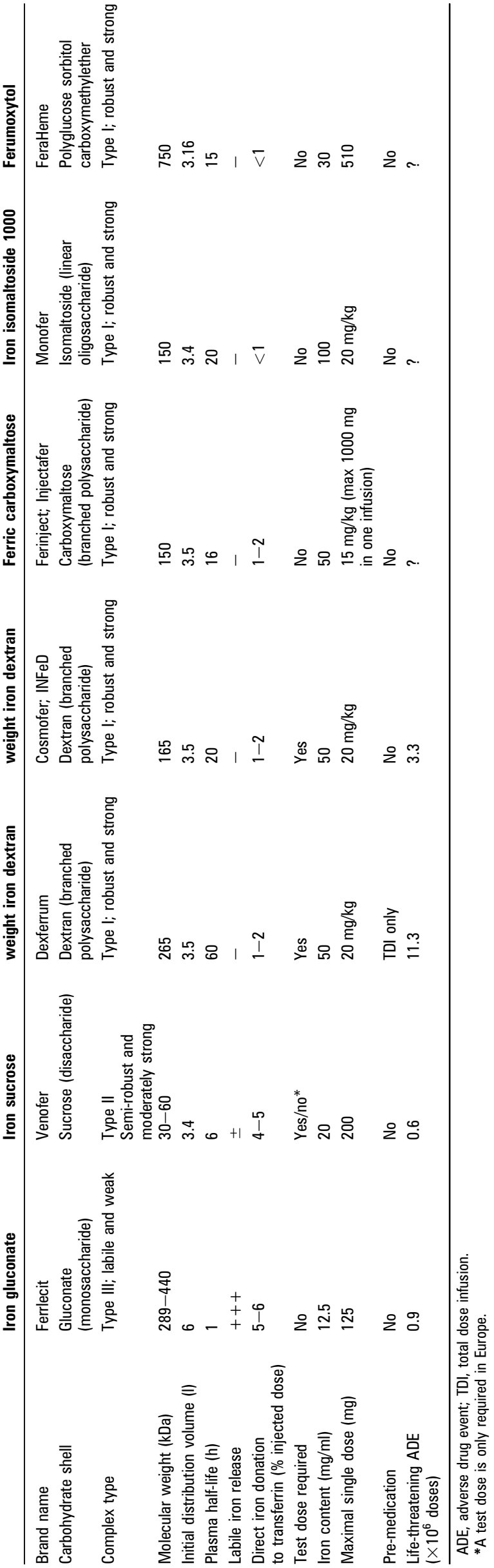


overload are at increased risk of infection. ${ }^{29}$ In contrast, in the peritoneal dialysis population, no increased risk of peritonitis was found in patients receiving with respect to those not receiving intravenous iron. ${ }^{30}$ In addition, a meta-analysis of six observational studies (807 patients) revealed that the administration of intravenous iron to patients undergoing major orthopaedic surgery led to a significant decrease in transfusion (RR $0.60,95 \%$ CI 0.50 to $0.72, \mathrm{p}<0.001)$ and infection rates $(R R$ $0.45,95 \%$ CI 0.32 to $0.63, \mathrm{p}<0.001) .{ }^{31}$ However, despite the absence of definitive clinical data, it seems sensible to avoid intravenous iron administration in the setting of acute infection, and to withhold intravenous iron in patients with pre-treatment ferritin values $>500 \mathrm{ng} / \mathrm{ml}^{18}$ On the other hand, the available evidence relating intravenous iron administration to atherogenesis is indirect, and there is little evidence that intravenous iron adversely affects survival in patients with dialysis-dependent chronic kidney disease. Nevertheless, the evidence argues for caution, not complacency, in prescribing intravenous iron. ${ }^{20}$

\section{IRON OVERLOAD}

In idiopathic iron-overload disease and primary haemochromatosis, hepcidin levels are disproportionately low for the degree of iron overload. This is due to abnormalities in the genes encoding HFE (haemochromatosis type 1), haemojuvelin (HJV; juvenile haemochromatosis $2 \mathrm{a}$ ), and transferrin receptor 2 (TfR2; haemochromatosis type 3); these abnormalities cause a dysregulation of hepcidin production. The exceptions are the mutations that affect hepcidin itself (juvenile haemochromatosis $2 b$ ) or ferroportin (haemochromatosis type 4).

Low plasma hepcidin leads to high ferroportin levels, which allow increased iron uptake, hepatic iron overload, and low levels of iron stored in macrophages. ${ }^{32-34}$ In addition, as transferrin becomes saturated in iron-overload states, non-transferrinbound iron appears. Part of this labile plasma iron is highly reactive, inducing free radical formation. Free radicals are responsible for the parenchymatous cell injury associated with iron-overload syndromes.

Although at least 32 mutations of the HFE gene have been described, the most common form of haemochromatosis type 1 results from the missense Cys282Tyr mutation of the gene. Haemochromatosis type 1 is a disease of variable penetrance and considerable heterogeneity, but the vast majority of patients with haemochromatosis type 1 are homozygous for the Cys282Tyr mutation. ${ }^{35}$ The mutant Cys282Tyr HFE protein is unable to bind $\beta_{2}$ microglobulin and fails to reach the cell membrane, resulting in a misfolded, non-functional protein. ${ }^{36}$ Mutations of the ferroportin gene (haemochromatosis type 4) may result in a loss of iron-export capacity, with hyperferritinaemia, but without elevation of transferrin saturation, and macrophage iron overload, or in a loss in hepcidin-binding activity, which is associated with iron overload. ${ }^{33} 37$

In contrast, under conditions of secondary iron overload due to chronic transfusion therapy (eg, in major thalassaemia, aplastic anaemia, etc), plasma hepcidin levels are elevated, resulting in degradation of ferroportin. Diferric transferrin levels, which are increased in iron overload, increase the expression of TfR2 at the hepatocyte membrane. Binding of diferric transferrin to TfR2 inhibits HJV cleavage by furin, thus inhibiting the release of soluble HJV and resulting in cell-surface HJV-mediated enhanced responsiveness to bone morphogenetic proteins and elevated hepcidin levels. ${ }^{33} 34$ The reduced levels of ferroportin limit the uptake of iron from the intestine, reduce the export from macrophages, and increase iron storage.
In iron-loading anaemia, such as chronic haemolytic anaemia (eg, thalassaemia intermedia, pyruvate kynase deficiency, etc) or anaemia with ineffective erythropoiesis (eg, congenital dyserythropoetic anaemias, syderoblastic anaemia, low-grade myelodysplastic syndromes, etc), iron overload is caused by low levels of hepcidin. Patients with these types of anaemia are seldom transfused. Despite increased iron stores, increased erythropoiesis releases a number of growth differentiation factors, which in turn suppress liver hepcidin production by inhibiting inflammatory and iron-sensing pathways. ${ }^{38}$ This hierarchy of individual stimuli determines the level of circulating hepcidin. ${ }^{39}$

\section{Assessment of iron overload}

The concentration and total amounts of iron in different tissues are critical parameters that determine clinical outcome in all forms of systemic iron overload, independent of whether the iron overload is caused by upregulated intestinal iron absorption (ie, hereditary haemochromatosis, thalassaemia intermedia, or iron-loading anaemia) or by blood transfusion (ie, thalassaemia major, sickle cell disease, aplastic or refractory anaemia, or myelodysplastic syndrome $)^{40}$ (box 2 ).

Accumulation of free iron in tissues characteristically occurs over decades in patients with hereditary disorders of iron metabolism, but it may take place within a few years in transfusion-dependent patients. The diagnosis of iron overload requires sequential steps. Clinical evaluation, biochemical testing, assessment of total body iron, and molecular tests concur to reach the correct diagnosis. Several comprehensive diagnosis and therapeutic algorithms have been recently proposed (eg, see the algorithm proposed by Pietrangelo ${ }^{34}$ ).

\section{Box 2 Classification of iron-overload syndromes}

Hereditary haemochromatosis

- Type I due to HFE mutations

- Type II (juvenile haemochromatosis)

- Haemojuvelin mutations

- Hepcidin mutations

- Type III due to transferrin receptor 2 mutations

- Type IV

- Without hepcidin resistance (ferroportin disease)

- With hepcidin resistance (true iron overload)

Hereditary hyperferritinaemia without iron overload

- With cataract

Without cataract

Transfusion-dependent iron overload (thalassaemia major)

Iron-loading anaemia

- Haemolytic anaemia (thalassaemia intermedia)

- Ineffective erythropoiesis (congenital dyserythropoietic anaemia)

Other

- Congenital

- Aceruloplasminaemia

- DMT1 deficiency

- A(hypo)transferrinaemia

- Acquired

- Parenteral iron

- Haemodialysis

- Liver disease (alcoholic, dysmetabolic, viral)

- Neonatal haemochromatosis

- Bantu siderosis 
However, we will review the four-step algorithm proposed by Camaschella, as we consider that it may be more useful and easy to follow in everyday clinical practice. ${ }^{41}$

The first diagnostic step is to suspect that iron overload is present (eg, fatigue, dark skin, arthralgia, hepatomegaly, cardiomyopathy, endocrine disorder, etc). However, this is frequently based on the findings of abnormal TSAT (>45\%) and/ or increased serum ferritin (>200 ng/ml in women, $>300 \mathrm{ng} / \mathrm{ml}$ in men). In practice, one can assume that normal transferrin saturation excludes the diagnosis of iron overload. The only exception is the fortuitous coexistence of an inflammatory syndrome, which can mask the increase in TSAT, and this is why it is essential to check CRP together with transferrin saturation. Conversely, increased TSAT can be found in non-iron-overload conditions such as marked cytolysis (eg, acute hepatitis), which increases plasma serum iron and/or hepatic failure, which decreases plasma transferrin concentrations. On the other hand, in the presence of high serum ferritin, without increased TSAT, other causes of hyperferritinaemia should be ruled out (eg, alcohol, cell necrosis, metabolic disorder, inflammation, cancer, etc). ${ }^{34}$ Any difficulty in interpretation of TSAT levels can be easily resolved by the clinical context, and by checking $\mathrm{Hb}$ (to exclude chronic inflammatory anaemia), and transaminases and prothrombin index (to exclude hepatic disease). ${ }^{41}$

A new, recently described, congenital entity presenting with high ferritin levels, normal TSAT and plasma creatinine levels is the hereditary hyperferritinaemia cataract syndrome (HHCS). However, cases of HHCS coursing without clinical or biochemical signs of iron overload have been recently described in most western European countries, Australia, Canada and the USA. This dominant autosomic condition is associated with mutations in the gene of ferritin subunit L, located in chromosome 19. HHCS should be included in the differential diagnosis of hyperferritinaemia. ${ }^{42}$ Moreover, a missense mutation in the $\mathrm{L}$ ferritin coding sequence has been found in patients with hyperferritinaemia without cataracts and with an unusually high percentage of ferritin glycosylation. ${ }^{43}$

The second diagnostic step is to exclude mutations in the HFE gene, especially in Caucasian patients. In clinical practice the HFE genotype is often considered 'wild type' when the presence of the two common (Cys282Tyr and His63Gly) mutations has been excluded, because other mutations in HFE are extremely rare. Nevertheless, the possibility of a familial disorder should always be investigated: a dominant disorder generally suggests ferroportin disease. ${ }^{41}$

If the diagnosis of HFE haemochromatosis is not confirmed, the third diagnostic step is to demonstrate increased total body iron, before starting expensive and time-consuming searches for mutations in other genes. Iron stores can be assessed by direct and indirect methods. The reference method for direct biochemical measurement of non-haem iron is a liver biopsy. Patients with liver iron concentration (LIC) greater than approximately $15 \mathrm{mg} / \mathrm{g}$ liver dry weight appear to be at increased risk for cardiac complications and early death. ${ }^{44}$ Thresholds for hepatocellular injury and fibrosis or cirrhosis are above LIC levels of approximately $22 \mathrm{mg} / \mathrm{g}$ liver dry weight. ${ }^{45}$ Although it is an invasive procedure, expensive, and subject to sampling errors, with a relatively high total complication rate, a liver biopsy is valuable in diagnosing non-HFE haemochromatosis for assessing stage of the disease (which is especially important in the severe juvenile form), and the distribution of iron (Kupffer cells versus hepatocytes, which can point to a more precise diagnosis, as iron accumulation in Kupffer cells is typical for ferroportin disease). ${ }^{41}$
Although it is not feasible for anaemic and transfusiondependent patients, quantitative phlebotomy is another reference method to evaluate storage iron in patients with hereditary haemochromatosis. ${ }^{46}$ However, cost, inconvenience and sideeffects limit its use. On the other hand, knowing that each gram of $\mathrm{Hb}$ contains $3.4 \mathrm{mg}$ iron, the precise amount of transfusional iron, as well as the amount of iron removed by phlebotomy, can be easily and accurately estimated.

In recent years, there has been increasing interest in noninvasive iron measurement, especially of the liver and heart, in patients with iron overload (table 3). Measurement of serum ferritin, which is available worldwide, relatively well standardised and inexpensive, is currently the most convenient laboratory test available to estimate total body iron. Iron overload is suggested by serial serum ferritin levels consistently more than $1000 \mathrm{ng} / \mathrm{ml}$. In addition, it remains an essential monitoring parameter in intervals between liver iron measurements, and has a positive correlation with morbidity and mortality. However, it is worth noting that ferritin is an indirect measurement of iron burden, and confounding factors, such as the specific disease, chelation treatment, inflammation, vitamin C deficiency, oxidative stress, hepatocyte dysfunction and increased cell death, have to be taken into account. Other laboratory tests with potential utility in iron overload include plasma nontransferrin-bound iron (serum transferrin saturation and plasma non-transferrin bound iron are independent predictors of cardiac toxicity from iron overload), ${ }^{47}$ serum transferrin receptor concentration, and labile plasma iron. However, these tests are not generally available for routine clinical application.

Liver iron measurements can now routinely be performed by quantitative MRI using the transverse magnetic relaxation rate R2 or R2* $(1 / \mathrm{T} 2 *)$, whereas the superconductive quantum interference device for biomagnetic susceptometry is currently too expensive for clinical use, and very few machines are available worldwide. ${ }^{40} 48$ As for the heart, the single-breath-hold multi-echo MRI-R2* method has become a standard modality for iron measurements (as it correlates closely with the results of cardiac biopsy in patients with high or low levels of heart iron deposition). ${ }^{49} 50$ Cardiac and liver iron assessment is becoming the standard for evaluating the clinical response to chelation treatment. ${ }^{51}$ In other tissues, such as the pancreas, pituitary and brain, different MRI methods are employed, but their clinical benefit has yet to be proven (for a detailed review, see Fischer and Harmatz $(2009)^{48}$ ).

The fourth step is the precise molecular diagnosis, which requires demonstration of the nucleotide change at the DNA level. However, as molecular diagnosis is expensive, timeconsuming and, in some cases, unable to provide a clear diagnosis, its utility is sometimes questioned. As non-HFE haemochromatosis is rare and acquired iron overload is common, molecular tests for patients with TfR2, HJV, hepcidin and ferroportin mutation should be carefully selected taking into account the presence of increased TSAT, ferritin and LIC, and clinical complications, age and family transmission pattern (figure 2).

\section{Management of iron overload \\ Blood removal}

The previous rationale for blood removal for all patients with haemochromatosis was that iron depletion would reduce or eliminate the potential for iron-mediated tissue injury. This may prevent some complications of haemochromatosis and/or diminish their intensity following iron depletion. It may decrease dyspnoea, pigmentation, fatigue, arthralgia or hepatomegaly, or 
Table 3 Main diagnostic tools for assessment of iron overload

\begin{tabular}{|c|c|c|}
\hline Parameter & Advantages & Disadvantages \\
\hline Transferrin saturation & Relatively non-invasive; inexpensive; routine laboratory assay & $\begin{array}{l}\text { Values confounded by inflammation, liver function, and } \\
\text { ascorbate status }\end{array}$ \\
\hline Serum ferritin & $\begin{array}{l}\text { Easy to assess; inexpensive; repeat measures are useful for } \\
\text { monitoring chelation therapy; positive correlation with } \\
\text { morbidity and mortality }\end{array}$ & $\begin{array}{l}\text { Indirect measurement of iron burden; fluctuates in response to } \\
\text { inflammation, abnormal liver function, metabolic deficiencies; } \\
\text { serial measurement required }\end{array}$ \\
\hline Liver biopsy & $\begin{array}{l}\text { Direct measurement of LIC; validated reference standard; } \\
\text { quantitative, specific and sensitive; allows for measurement of } \\
\text { non-haem storage iron; provides information on liver histology/ } \\
\text { pathology; positive correlation with morbidity and mortality }\end{array}$ & $\begin{array}{l}\text { Invasive, painful procedure associated with potentially serious } \\
\text { complications; risk of sampling error, especially in patients } \\
\text { with cirrhosis; requires skilled physicians and standardised } \\
\text { laboratory techniques }\end{array}$ \\
\hline LIC assessment by SQUID & $\begin{array}{l}\text { Linear correlation with LIC assessed by biopsy; may be } \\
\text { repeated frequently }\end{array}$ & $\begin{array}{l}\text { Indirect measurement of LIC; limited availability; high cost; } \\
\text { highly specialised equipment requires dedicated technician; not } \\
\text { validated for LIC assessment and may underestimate levels }\end{array}$ \\
\hline Quantitative iron assessment by MRI & $\begin{array}{l}\text { The technique known as R2 (spin echo) MRI is a validated and } \\
\text { standardised method for measuring LIC; cardiac iron levels can } \\
\text { be rapidly and effectively assessed using a technique known as } \\
\text { T2* (gradient echo) MRI, which is becoming the new standard } \\
\text { method; potentially widely available; pathological status of liver } \\
\text { and heart can be assessed in parallel }\end{array}$ & $\begin{array}{l}\text { Indirect measurement of iron concentration in liver and heart; } \\
\text { requires MRI imager with dedicated imaging method; } \\
\text { methodology remains to be standardised and validated for } \\
\text { assessment of cardiac iron }\end{array}$ \\
\hline
\end{tabular}

LIC, liver iron concentration; SQUID, superconductive quantum interference device.

improve control of diabetes mellitus and left ventricular diastolic function. However, the course of hepatic cirrhosis, and increased risk of primary liver cancer, hyperthyroidism or hypothyroidism is usually not changed. ${ }^{32}$

For most patients with haemochromatosis and iron overload, standard therapy is the weekly removal of blood to bring the ferritin level into the low reference range $(20-50 \mathrm{ng} / \mathrm{ml})$, followed by a life-long maintenance phlebotomy schedule for maintaining ferritin levels at approximately $50 \mathrm{ng} / \mathrm{ml}$, for preventing or reversing liver fibrosis. ${ }^{32} 52$ The number of units to be removed can be calculated taking into account that, in the absence of hepatic necrosis or another source of inflammation that causes hyperferritinaemia, $1 \mathrm{ng} / \mathrm{ml}$ ferritin corresponds to nearly $8 \mathrm{mg}$ mobilisable iron and a $500 \mathrm{ml}$ blood unit contains approximately $200 \mathrm{mg}$ iron. Thus, a patient whose serum ferritin is $1000 \mathrm{ng} / \mathrm{ml}$ is likely to undergo the removal of 40 units of blood to achieve iron depletion. Removal of blood can be accomplished by conventional phlebotomy or erythrocytapheresis.

Conventional phlebotomy (250-500 ml once or twice weekly during the initial phase, depending on patient characteristics and the level of iron overload, followed by $500 \mathrm{ml}$ every $2-4$ months for the rest of the life) is excellent for iron depletion, but requires normal erythropoiesis and repeated visits to a healthcare facility, and some patients report intolerance. ${ }^{32}$ According to recent US
Figure 2 A simplified algorithm for the diagnosis of haemochromatosis (modified from Karnon et al $(2008)^{58}$ ). $A D$, autosomal dominant inheritance; $A R$, autosomal recessive inheritance; Ft, ferritin; LIC, liver iron concentration; FPN, ferroportin; Hamp, hepcidin gene; HJV, hemojuvelin; TfR2, transferrin receptor 2; TS.

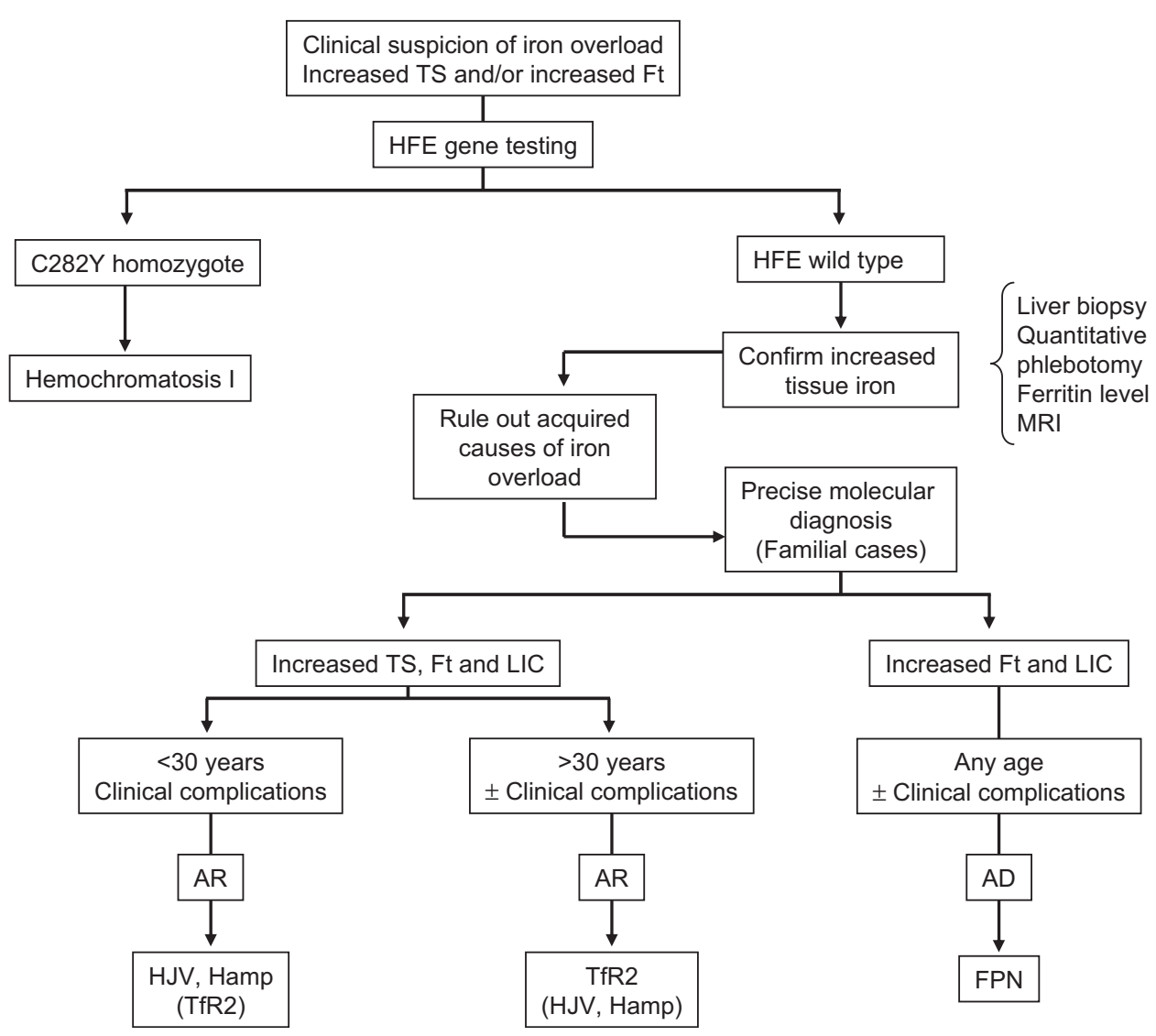


Table 4 Some characteristics of the different iron chelators

\begin{tabular}{|c|c|c|c|}
\hline & Deferoxamine messylate & Deferiprone & Deferasirox \\
\hline Brand name & Desferal & Ferriprox & Exjade \\
\hline Usual dosage & $\begin{array}{l}\text { Initial: } 40 \mathrm{mg} / \mathrm{kg} / \text { day (five times weekly); } \\
\text { maintenance: } 20-40 \mathrm{mg} / \mathrm{kg} / \text { day }\end{array}$ & $\begin{array}{l}\text { Initial: } 75 \mathrm{mg} / \mathrm{kg} / \text { day; maintenance: } \\
75-100 \mathrm{mg} / \mathrm{kg} / \text { day }\end{array}$ & $\begin{array}{l}\text { Initial:20 mg/kg/day; maintenance: } \\
10-30 \mathrm{mg} / \text { day }\end{array}$ \\
\hline Route of administration & Subcutaneous, intravenous, $8-10 \mathrm{~h} /$ day & Oral, three times daily & Oral, once daily \\
\hline $\begin{array}{l}\text { Chelator-to-iron binding } \\
\text { molar ratio }\end{array}$ & $1: 1$ & $3: 1$ & $2: 1$ \\
\hline Plasma half-life & $5-10 \min$ & $47-143 \mathrm{~min}$ & $8-16 \mathrm{~h}$ \\
\hline Excretion & Urinary, faecal & Urinary & Faecal, urinary \\
\hline Advantages & $\begin{array}{l}\text { Widely available, inexpensive; extensive } \\
\text { clinical experience }\end{array}$ & $\begin{array}{l}\text { Good chelation of hepatic and cardiac } \\
\text { iron, inexpensive; extensive clinical } \\
\text { experience }\end{array}$ & $\begin{array}{l}\text { Good chelation of hepatic and cardiac } \\
\text { iron; no growth abnormalities or } \\
\text { agranulocytocis }\end{array}$ \\
\hline Disadvantages & $\begin{array}{l}\text { Inadequate chelation of cardiac iron; } \\
\text { compliance problems }\end{array}$ & $\begin{array}{l}\text { Variable chelation of hepatic and cardiac } \\
\text { iron in some cases; dosage schedule }\end{array}$ & May be distasteful for younger patients \\
\hline Side-effects & $\begin{array}{l}\text { Auditory, ocular and neurological toxicity; } \\
\text { growth and skeletal abnormalities }\end{array}$ & $\begin{array}{l}\text { Neutropenia and agranulocytosis; muscle } \\
\text { and joint pain; gastric intolerance; hepatic } \\
\text { dysfunction; zinc deficiency }\end{array}$ & $\begin{array}{l}\text { Gastrointestinal disturbances; rash; and } \\
\text { possible renal toxicity }\end{array}$ \\
\hline Monitoring & Annual audiometry and eye examinations & $\begin{array}{l}\text { Weekly blood count testing; transaminase } \\
\text { monthly for } 3-6 \text { months and every } \\
6 \text { months thereafter }\end{array}$ & $\begin{array}{l}\text { Monthly serum creatinine, urinary protein } \\
\text { and transaminase testing; regular } \\
\text { assessment or iron burden every } 3-6 \\
\text { months for dosage adjustment }\end{array}$ \\
\hline Approved indications & Iron overload of any aetiology & $\begin{array}{l}\text { Iron overload in thalassaemia major when } \\
\text { contraindication or failure of } \\
\text { deferioxamine in thalassaemia major }\end{array}$ & $\begin{array}{l}\text { Transfusional iron overload in thalas- } \\
\text { saemia major; contraindication or failure } \\
\text { of deferioxamine in thalassaemia major } \\
\text { and other transfusional iron overload } \\
\text { status }\end{array}$ \\
\hline
\end{tabular}

Food and Drug Administration regulations, blood removed for therapeutic phlebotomy at blood donation facilities can be used as a means of augmenting the blood supply for transfusion (Title 21, Code of Federal Regulations, section 640.120 (21 CFR 640.120)). ${ }^{53}$ On the other hand, isovolaemic, large-volume erythrocytapheresis removes more blood erythrocytes per session than phlebotomy, while sparing plasma proteins, coagulation factors and platelets. Thus, therapeutic erythrocytapheresis is rapid, safe, and may be preferred in the initial phase for patients with severe iron overload. Although the cost of a single therapeutic erythrocytapheresis session is greater, the total costs to induce iron depletion are similar to or lower than those with therapeutic phlebotomy; however, the procedure has a limited availability (special apparatus and facilities, trained personnel, etc). ${ }^{54}$ Nevertheless, both options have similar adverse effects: transient hypovolaemia, fatigue ( $\mathrm{Hb}$ levels should not drop below $11 \mathrm{~g} / \mathrm{dl}$ ), increased iron absorption, citrate reaction (erythrocytapheresis only) or iron deficiency, if there is not an appropriate monitoring.

In contrast, except for patients with haemochromatosis who are unable to undergo phlebotomy therapy, iron chelation therapy is rarely ideal for patients with haemochromatosis because of cost, potential toxicity, and relative lack of documentation of benefits. Finally, dietary restrictions (eg, low intake of meat, avoidance of alcohol consumption, restrictive use of vitamin and mineral supplements, etc) and medications to reduce iron absorption (eg, proton pump inhibitors) seem rational approaches for patients with haemochromatosis, but they have not been evaluated in prospective randomised clinical trials. ${ }^{52}$

\section{Iron chelation therapy}

Management of iron overload and treatment of iron toxicity by chelation in patients with acquired iron overload (eg, transfusion-dependent anaemia) have been demonstrated to reduce iron burden and improve survival. According to recent consensus guidelines, patients with serial serum ferritin levels exceeding $1000 \mathrm{ng} / \mathrm{ml}$ and a total infused red blood cell volume of $120 \mathrm{ml} / \mathrm{kg}$ of body weight or more should be treated with chelation therapy.

\section{Take-home messages}

\section{Iron deficiency}

- In absolute iron deficiency (ID), iron stores are depleted; in functional iron deficiency, iron stores, although replete, cannot be mobilised as fast as necessary. These conditions may result in iron deficiency anaemia or anaemia of chronic disease (ACD), respectively. ACD may further evolve to $A C D+I D$.

- In iron deficiency status, laboratory tests may provide evidence of iron depletion in the body or reflect iron-deficient red cell production.

- Oral iron supplementation $(50-100 \mathrm{mg} /$ day) is adequate in most clinical conditions, although it is time-consuming and non-absorbed iron salts may lead to digestive intolerance and treatment discontinuation.

- Modern parenteral iron formulations are indicated in situations such as intolerance, contraindications or inadequate response to oral iron. With the exception of high molecular weight iron dextran, the acute safety differences among intravenous iron products are small and clinically irrelevant when given at the recommended doses.

\section{Iron overload}

- Serum ferritin is the basic parameter for iron overload management, but do not use it alone, be aware of its poor predictive value, and use the trend of repeated measures (iron load direction).

- Exclude HFE haemochromatosis, and measure liver iron concentration (iron load amount and 'buffer reserve') by biopsy or MRI, and assess the heart iron by MRI T2* (cardiac risk), at least once.

- In transfused patients, accurately record the iron input and do iron balance, where feasible.

- Integrate available tests for effective management of iron chelation. 


\section{Interactive multiple choice questions}

This JCP best practice article has an accompanying set of multiple choice questions (MCOs). To access the questions, click on BMJ Learning: Take this module on BMJ Learning from the content box at the top right and bottom left of the online article. For more information please go to: http://jcp.bmj.com/education Please note: the MCOs are hosted on BMJ Learning — the best available learning website for medical professionals from the BMJ Group. If prompted, subscribers must sign into JCP with their journal's username and password. All users must also complete a one-time registration on BMJ Learning and subsequently log in (with a BMJ Learning username and password) on every visit.

Serum ferritin levels should be monitored every 3 months during chelation therapy to ensure that treatment adequately reduces iron levels. ${ }^{55-57}$ The main characteristics of the three iron chelating agents currently available, including usual dosage, route of administration, pharmacokinetics, advantages, disadvantages, side effects, monitoring and approved indications, are given in table 4.

Cost analyses comparing deferasirox with deferoxamine in the $\mathrm{UK}^{58}$ and the USA ${ }^{59}$ concluded that deferasirox is cost-effective compared with standard parenteral iron chelation therapy with deferoxamine, primarily due to the quality-of-life benefits derived from the simpler and more convenient mode of oral administration. First data from a phase I/II study using deferasirox in HFE-haemochromatosis suggest that a dose between 5 and $10 \mathrm{mg} / \mathrm{kg} /$ day is adequate to reduce iron burden, and a randomised trial comparing deferasirox versus phlebotomy is currently ongoing. ${ }^{60}$

Competing interests None to declare.

Provenance and peer review Commissioned; externally peer reviewed.

\section{REFERENCES}

1. Muñoz M, García-Erce JA, Remacha AF. Disorders of iron metabolism. Part 1: molecular basis of iron homeostasis. J Clin Pathol 2010. doi:10.1136/jcp.2010.079046.

2. Hersko C. Prevalence and causes of iron deficiency anaemia. In: Beaumont $C$, Beris $P$, Beuzard Y, Brugnara C, eds. Disorders of Iron Homeostasis, Erythrocytes, Erythropoiesis. Paris: European School of Haematology, 2006:409-19.

3. Cook JD. Diagnosis and management of iron-deficiency anaemia. Best Pract Res Clin Haematol 2005;18:319-32.

4. Weiss G, Goodnough LT. Anemia of chronic disease. N Engl J Med 2005;352:1011-23.

5. Beutler $\mathbf{E}$, Waalen J. The definition of anemia: what is the lower limit of normal of the blood hemoglobin concentration? Blood 2006;107:1747-50.

6. Goognough LT. The relevance of iron in erythropoietin-stimulated erythropoiesis. Semin Hematol 2006;43(Suppl 6):S3-S8.

7. Muñoz M, Villar I, García-Erce JA. An update on iron physiology. World J Gastroenterol 2009;15:4617-26.

8. Thomas C, Thomas L. Biochemical markers and hematologic indices in the diagnosis of functional iron deficiency. Clin Chem 2002:48:1066-76.

9. Theurl I, Aigner E, Theurl M, et al. Regulation of iron homeostasis in anemia of chronic disease and iron deficiency anemia: diagnostic and therapeutic implications. Blood 2009;113:5277-86.

10. Punnonen K, Irjala K, Rajamaki A. Serum transferrin receptor and its ratio to serum ferritin in the diagnosis of iron deficiency. Blood 1997;89:1052-7.

11. Beguin Y, Clemons GK, Pootrakul P, et al. Quantitative assessment of erythropoiesis and functional classification of anemia based on measurements of serum transferring receptors and erythropoietin. Blood 1993;81:1067-76.

12. Thomas L, Franck $\mathrm{S}$, Messinger $\mathrm{M}$, et al. Reticulocyte hemoglobin measurement-comparison of two methods in the diagnosis of iron-restricted erythropoiesis. Clin Chem Lab Med 2005;43:1193-202.

13. Brugnara C, Schiller B, Moran J. Reticulocyte hemoglobin equivalent (RetHe) and assessment of iron-deficient states. Clin Lab Haematol 2006;28:303-8.
14. Canals C, Remacha AF, Sarda MP, et al. Clinical utility of the new Sysmex XE 2100 parameter - reticulocyte hemoglobin equivalent - in the diagnosis of anemia. Haematologica 2005;90:1133-4.

15. Gisbert JP, Gomollón F. Common misconceptions in the diagnosis and management of anemia in inflammatory bowel disease. Am J Gastroenterol 2008;103:1299-307.

16. Crichton RR, Danielsson BG, Geisser P. Iron Therapy with Special Emphasis on Intravenous Administration, Bremen: UNI-Med Verlag AG, 2008.

17. Maniatis A. The role of iron in anaemia management: can intravenous iron contribute to blood conservation? ISBT Science Series 2008;3:139-43.

18. Beris $\mathbf{P}, \mathbf{M u n ̃ o z} \mathbf{M}$, García-Erce JA, et al. Perioperative anaemia management: consensus statement on the role of intravenous iron. Br J Anaesth 2008; 100:599-604.

19. Goodnough LT, Skikne B, Brugnara C. Erythropoietin, iron, and erythropoiesis. Blood 2000;96:823-33. PMID: 10910892.

20. Aronoff GR. Safety of intravenous iron in clinical practice: implications for anemia management protocols. J Am Soc Nephrol 2004;15:S99-106.

21. Silverstein SB, Rodgers GM. Parenteral iron therapy options. Am J Hematol 2004;76:74-8.

22. Fishbane S, Kowalski EA. The comparative safety of intravenous iron dextran, iron saccharate, and sodium ferric gluconate. Semin Dial 2000;13:381-4.

23. Danielson BG. Structure, chemistry, and pharmacokinetics of intravenous iron agents. J Am Soc Nephrol 2004;15:S93-8.

24. Lu M, Suh KR, Lee H-Z, et al. FDA review of ferumoxytol (Feraheme) for the treatment of iron deficiency anemia in adults with chronic kidney disease. Am $J$ Hematology 2010;85:315-19.

25. Coyne DW, Auerbach M. Anemia management in chronic kidney disease: Intravenous iron steps forward. Am J Hematology 2010;85:311-12.

26. Muñoz M, Breymann C, García-Erce JA, et al. Efficacy and safety of intravenous iron therapy as an alternative/adjunct to allogeneic blood transfusion. Vox Sang 2008;94:172-83

27. Rodgers GM, Auerbach $\mathrm{M}$, Cella $\mathrm{D}$, et al. High-molecular weight iron dextran: a wolf in sheep's clothing? J Am Soc Nephrol 2008;19:833-4.

28. Rodgers GM, Becker PS, Bennett CL, et al. Cancer- and chemotherapy-induced anemia. J Natl Compr Canc Netw 2008;6:536-64.

29. Weiss G. Iron and immunity: a double-edged sword. Eur J Clin Invest 2002;32(Suppl 1):70-8.

30. Vychytil A, Haag-Weber M. Iron status and iron supplementation in peritoneal dialysis patients. Kidney Int 1999;55(Suppl):S71-8.

31. García-Erce JA, Cuenca J, Gómez-Ramírez S, et al. Posibilidades de tratamiento de la anemia perioperatoria en cirugía ortopédica y traumatología. Anemia 2009; $:$ :17-27

32. Edward Co. Hemochromatosis. In: Greer JP, Foester J, Rodgers GM, et al, eds. Wintrobe's Clinical Hematology. 12th edn. Philadelphia: Wolters Kluwer/Lippincott, Williams \& Wikins, 2009:857-80.

33. Lee PL, Beutler E. Regulation of hepcidin and iron-overload disease. Annu Rev Pathol Mech Dis 2009:4:489-515.

34. Pietrangelo A. Hereditary hemochromatosis: pathogeneis, diagnosis, and treatment. Gastroenterology 2010;139:393-408.

35. Adams PC, Barton JC. Haemochromatosis. Lancet 2007:370:1855-60

36. Feder J, Tsuchihashi Z, Irrinki A, et al. The hemochromatosis founder mutation in HLA-H disrupts beta2-microglobulin interaction and cell surface expression. J Biol Chem 1997;272:14025-8

37. Vach V, Remacha A, Altès A, et al. Autosomal dominant hemochromatosis associated with two novel Ferroportin 1 mutations in Spain. Blood Cells Mol Dis 2006; $\mathbf{3 6}: 41-5$

38. Tamary H, Shalev H, Perez-Avraham G, et al. Elevated growth differentiation factor 15 expression in patients with congenital dtserythropoeitc anemia type I. Blood 2008;112:5241-4.

39. Huang $\mathbf{H}$, Constante M, Layoun A, et al. Contribution of STAT3 and SMAD4 pathways to the regulation of hepcidin by opposing stimuli. Blood 2009;113:3593-9.

40. Shander A, Sazama K. Clinical consequences of iron overload from chronic red blood cell transfusions, its diagnosis, and its management by chelation therapy. Transfusion 2010;50:1144-55.

41. Camaschela C. Diagnosis and treatment of non-HFE haemochromatosis. In: Beaumont C, Beris P, Beuzard Y, et al, eds. Disorder of Iron Homeostasis, Erythrocytes, Erytrhopoiesis. Paris: European School of Haematology, 2006:466-77.

42. García Erce JA, Cortés T, Cremonesi L, et al. [Hyperferritinemia-cataract syndrome associated to the HFE gene mutation. Two new Spanish families and a new mutation (A37T: "Zaragoza")]. Med Clin (Barc) 2006;127:55-8.

43. Kannengiesser C, Jouanolle AM, Hetet G, et al. A new missense mutation in the $L$ ferritin coding sequence associated with elevated levels of glycosilated ferritin in serum and absence of iron overload. Haematologica 2009;94:335-9.

44. Brittenham GM, Griffith PM, Nienhuis AW, et al. Efficacy of deferoxamine in preventing complications of iron overload in patients with thalassemia major. N Engl $J$ Med 1994;331:567-73.

45. Jensen PD, Jensen FT, Christensen T, et al. Relationship between hepatocellular injury and transfusional iron overload prior to and during iron chelation with desferrioxamine: a study in adult patients with acquired anemias. Blood 2003;101:91-6.

46. Morrison ED, Brandhagen DJ, Phatak PD, et al. Serum ferritin level predicts advanced hepatic fibrosis among U.S. patients with phenotypic hemochromatosis. Ann Intern Med 2003:138:627-33.

47. Ballas SK. Iron overload is a determinant of morbidity and mortality in adult patients with sickle cell disease. Semin Hematol 2001;38(Suppl 1):30-6. 
48. Fischer R, Harmatz PR. Non-invasive assessment of tissue iron overload. Hematology Am Soc Hematol Educ Program 2009:215-21.

49. Mavrogeni SI, Markussis V, Kaklamanis L, et al. A comparison of magnetic resonance imaging and cardiac biopsy in the evaluation of heart iron overload in patients with beta-thalassemia major. Eur J Haematol 2005;75:241-7.

50. Kirk $\mathbf{P}$, Roughton M, Porter JB, et al. Cardiac T2* magnetic resonance for prediction of cardiac complications in thalassemia major. Circulation 2009;120:1961-8.

51. Wood JC, Kang BP, Thompson A, et al. The effect of deferasirox on cardiac iron in thalassemia major: impact of total body iron stores. Blood 2010:116:537-43.

52. Adams PC, Barton JC. How I treat hemochromatosis. Blood 2010;116:317-25.

53. Power T, Adams PC. Hemochromatosis patients as voluntary blood donors. Can J Gastroenterol 2004;18:393-6.

54. Rombout-Sestrienkova E, van Noord PA, van Deursen CT, et al. Therapeutic erythrocytapheresis versus phlebotomy in the initial treatment of hereditary hemochromatosis-A pilot study. Transfus Apher Sci 2007:36:261-7.

55. Gattermann N, Porter J, Lopes LF, et al. Consensus statement on iron overload in myelodysplastic syndromes. Hematol Oncol Clin 2005;19(Suppl 1):18-25.
56. Mittelman M, Lugassy G, Merkel D, et al. Iron chelation therapy in patients with myelodysplastic syndromes: consensus conference guidelines. Isr Med Assoc J 2008:10:374-6.

57. Gattermann N. Guidelines on iron chelation therapy in patients with myelodysplastic syndromes and transfusional iron overload. Leuk Res 2007;31 (Suppl.3):S10-15

58. Karnon J, Tolley K, Oyee J, et al. Cost-utility analysis of deferasirox compared to standard therapy with desferrioxamine for patients requiring iron chelation therapy in the United Kingdom. Curr Med Res Opin 2008:24:1609-21.

59. Delea TE, Sofrygin 0, Thomas SK, et al. Cost effectiveness of once-daily oral chelation therapy with deferasirox versus infusional deferoxamine in transfusiondependent thalassemia patients: US healthcare system perspective. Pharmacoeconomics 2007;25:329-42

60. Phatak PD.Brissot P, Bonkovsky H, et al. A Phase I/II, open-label, dose-escalation trial of once-daily oral chelator deferasirox to treat iron overload in HFE-related hereditary hemochromatosis: final results of the core study. Blood (ASH Annual Meeting Abstracts) 2009;114:1514.

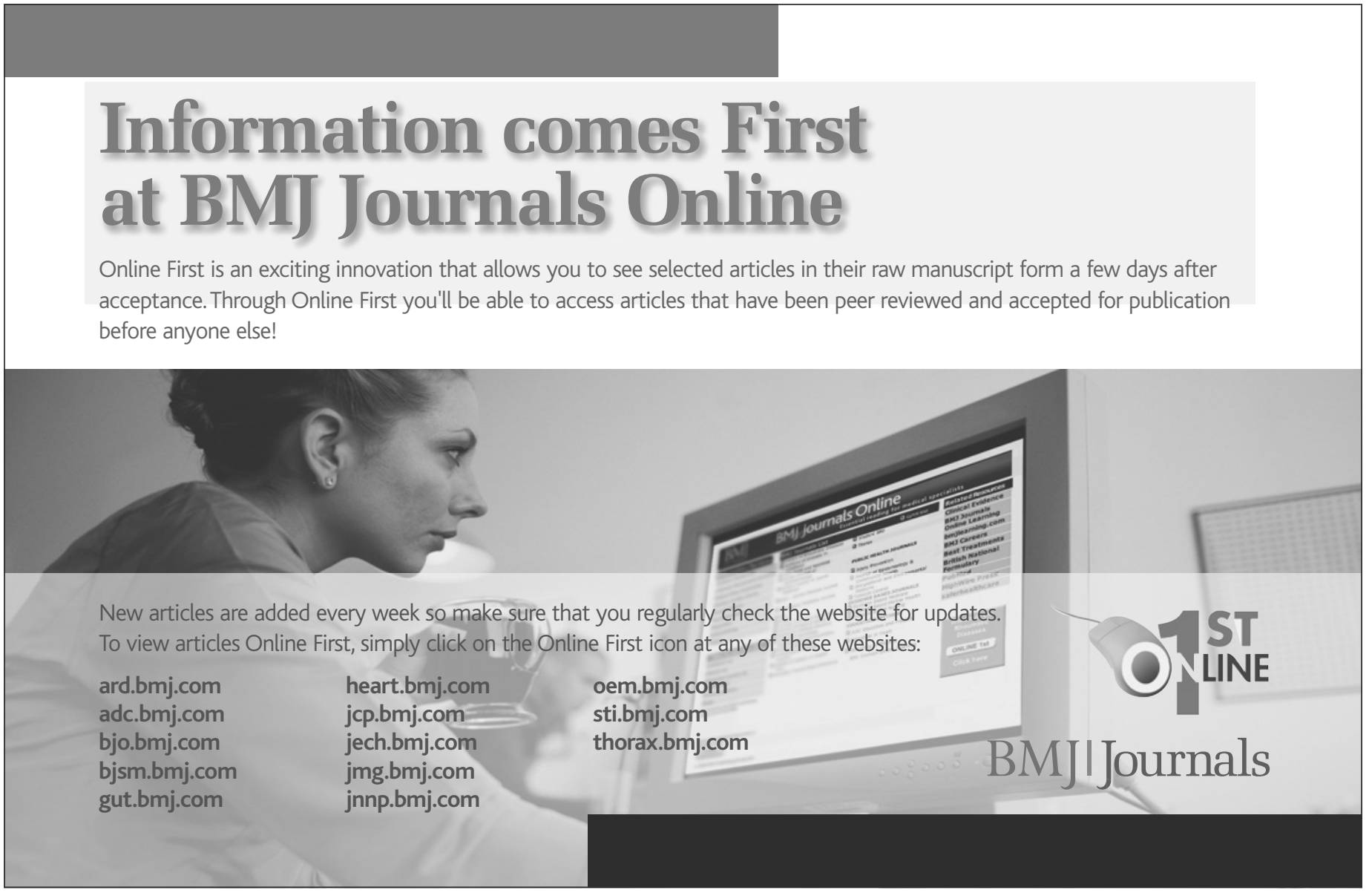

